\title{
ELECTRO-THERMO-MECHANICAL ANALYSIS OF ACTUATOR STRUCTURE MADE OF FUNCTIONALLY GRADED MATERIAL
}

\author{
JURAJ PAULECH*, VLADIMIR KUTIS*, JUSTIN MURIN*, \\ GABRIEL GALIK* AND VLADIMIR GOGA* \\ * Department Applied Mechanics and Mechatronics \\ Institute of Automotive Mechatronics \\ Faculty of Electrical Engineering and Information Technology \\ Slovak University of Technology in Bratislava \\ 81219 Bratislava, Slovak Republic \\ e-mail: juraj.paulech@stuba.sk,www.stuba.sk
}

Key words: Actuator, Electro-Thermo-Mechanical Analysis, Special FEM equations, Functionally Graded Materials.

\begin{abstract}
.
The paper deals with a new approach in analyzing of the actuator systems made of Functionally Graded Materials (FGM) using our new beam finite elements. Weak coupled electro-thermomechanical analysis and spatial continuous variation of material properties are considered for chosen actuator structure. This electrically driven actuator is simple-shaped due to properly chosen variation of material properties to ensure functionality of the actuator at material and physical level instead of the geometric shape level. The solution results will be compared with those obtained by using solid elements of a FEM commercial program.
\end{abstract}

\section{INTRODUCTION}

Actuator is a mechatronic system that transforms chosen type of energy into the mechanical displacement and mechanical force. These actuators can be made of traditionally materials (e.g. metals) but also of advanced materials such as Functionally Graded Materials (FGM). FGM is built as a mixture of two or more constituents and the variation of macroscopic material properties of the system can be induced by variation of both the volume fractions of the constituents and their material properties. Using such materials, the actuator can be simple shaped and its effectiveness, particularly for Micro-Electro-Mechanical Systems (MEMS), will be enhanced.

Classic shape of actuator (Figure 1a) can be replaced by new type - simply-shaped actuator (Figure 1b) where functionality is caused by varying material properties.

a)

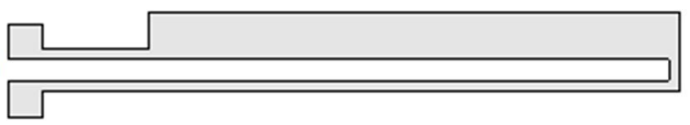

b)

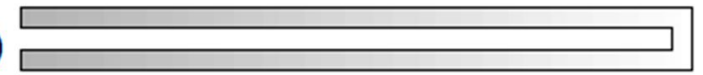

Figure 1: a) Classic shape of MEMS actuator, b) New shape of FGM actuator 
Functionality of the classic actuator is based on its shape that contains narrow parts of the actuator with higher resistance to reach higher electric heating of such parts, or to create mechanical joints that ensure simple bending of the actuator. New type of actuator made of FGM can be simple-shaped and above-mentioned functionality is ensured at material level where mixture of two material constituents is chosen such way to ensure change in material properties in given parts of the actuator and such to reach its proper (or even optimal) functionality.

Computer modelling and analysing of structures made of FGM can be performed in classical way (e. g. using computer tools based on Finite Element Method - FEM), where spatial change of material properties has to be included in the models that leads to relatively complicated models when considering fine change of material properties conditions.

Our approach for modelling and analysing of FGM structures is based on new link and beam finite elements derived for FGM, where whole parts of such structures are modelled using these new elements and the FEM model is relatively simple and easy to compute.

\section{FEM EQUATIONS FOR COUPLED ELECTRO - THERMO - MECHANICAL}

\section{ANALYSIS}

\section{Figure 2a presents simple link / beam FGM structure for which new FEM equations for} coupled electro-thermo-mechanical analysis will be derived.
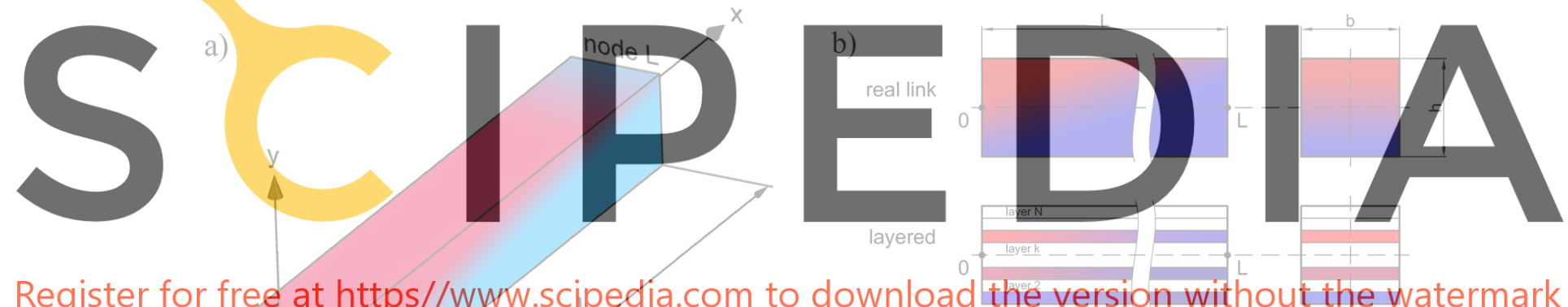

Register for free at https//wyrw.scipedia.com to download the version without the watermark
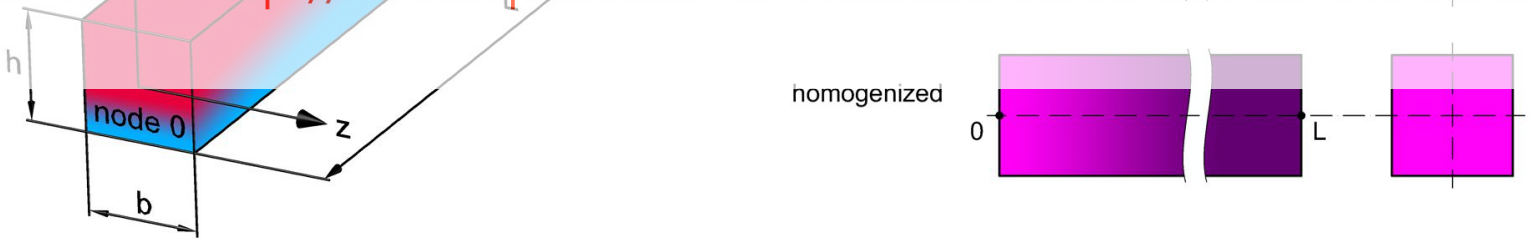

Figure 2: a) FGM 2-nodal link with its dimensions and illustrative change of material properties, b) homogenization process using multilayer method

Prior to the derivation process of the new FEM equations it is necessary to implement homogenization techniques (extended mixture rule [1] and multilayer method [2, 3]) that convert spatial change of material properties (caused by chosen mixture of the constituents) into equivalent one-dimensional change of material properties for each link or beam of the FGM actuator structure. This 1D change of effective material properties is only in longitudinal direction ( $x$ axis) of the link / beam, Figure $2 b$.

Derivation process for electro-thermo-mechanical element is based on differential equations for electric, thermal and structural fields for 1D type of analysis, respectively. Because of semi- 
analytical method used in the derivation process [4] all quantities in following equations are the polynomial functions of $x$.

\subsection{Differential equations}

Homogeneous 1D static differential equation for FGM (with non-constant coefficients on the left-hand side) for electric field with boundary conditions has a form:

$$
\begin{gathered}
-\sigma(x) \frac{d^{2} \varphi(x)}{d x^{2}}-\frac{d \sigma(x)}{d x} \frac{d \varphi(x)}{d x}=0 \\
\varphi(0)=\varphi_{0} \quad J(L)=J_{L}
\end{gathered}
$$

where $x[\mathrm{~m}]$ is the longitudinal coordinate, $\varphi(x)[\mathrm{V}]$ is the electric potential, $\sigma(x)[\mathrm{S} / \mathrm{m}]$ is the specific electric conductivity and $J(x)\left[\mathrm{Am}^{-2}\right]$ is the current density.

Static differential equation for heat transfer with non-constant auxiliary thermal source $Q(x)\left[\mathrm{W}^{-3}\right]$ in the volume of the link, with non-constant convective heat transfer coefficient $\alpha(x)\left[\mathrm{Wm}^{-2} \mathrm{~K}^{-1}\right]$ from the link surface and coupled to the electric field, has a form (2). One-way coupling between the electric and thermal field is provided by Joule heat $P_{J I}(x)\left[\mathrm{Wm}^{-3}\right]$, that can be calculated as one of the outputs from electric analysis and it enters the thermal analysis as volume heat (beside or instead of $Q(x)$ ).

$$
-\lambda(x) \frac{d^{2} T(x)}{d x^{2}}-\frac{d \lambda(x)}{d x} \frac{d T(x)}{d x}+\alpha(x) T(x) \frac{O}{A}=P_{J 1}(x)+Q(x)+\alpha(x) T_{a m b} \frac{O}{A}
$$

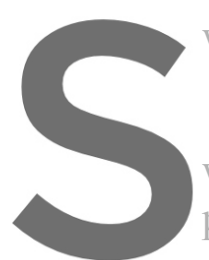

with boundary conditions, e.g

where $\lambda(x)\left[\mathrm{Wm}^{-1} \mathrm{~K}^{-1}\right]$ is the thermal conductiv

perimeter, $A\left[\mathrm{~m}^{2}\right]$

$q(x)\left[\mathrm{Wm}^{-2}\right]$ is the heat flux.
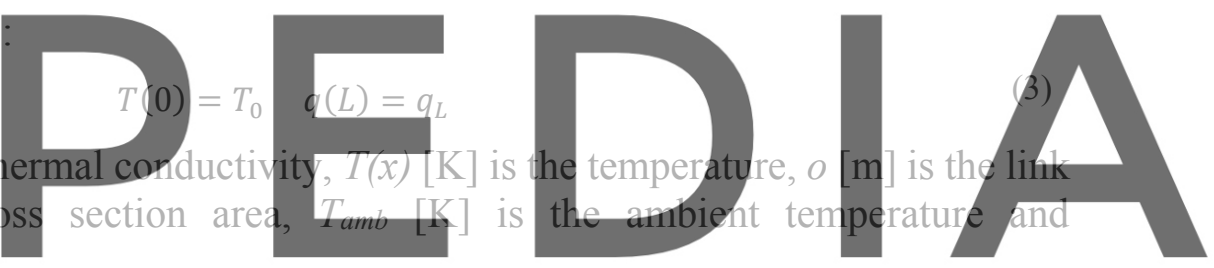

Homogeneous differential equation for structural analysis with effect of thermal expansion

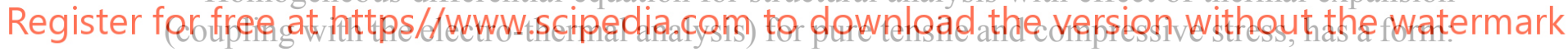

$$
\begin{gathered}
E_{N}^{H}(x) \frac{d^{2} u(x)}{d x^{2}}+\frac{d E_{N}^{H}(x)}{d x} \frac{d u(x)}{d x}= \\
=\frac{n(x)}{A}+\alpha_{t}(x) \Delta T(x) \frac{d E_{N}^{H}(x)}{d x}+\Delta T(x) E_{N}^{H}(x) \frac{d \alpha_{t}(x)}{d x}+E_{N}^{H}(x) \alpha_{t}(x) \frac{d \Delta T(x)}{d x}
\end{gathered}
$$

with boundary conditions, e.g.:

$$
u(0)=u_{0} \quad \sigma_{N}^{S}(L)=\sigma_{N, L}^{S}
$$

where $E_{N}{ }^{H}(\mathrm{x})[\mathrm{Pa}]$ is homogenized Young modulus for tension/compression, $u(x)[\mathrm{m}]$ is the displacement, $n(x)\left[\mathrm{Nm}^{-1}\right]$ are the distributed axial forces, $\alpha_{t}\left[\mathrm{~K}^{-1}\right]$ is the coefficient of thermal expansion and $\sigma_{N} s(x)[\mathrm{Pa}]$ is the structural normal stress.

Homogeneous differential equation for structural analysis for bending has a form:

$$
\frac{d^{2} w(x)}{d x^{2}}=-\frac{M(x)}{E_{M}^{H}(x) I_{y}}
$$

with boundary conditions, e.g.: 


$$
w(0)=w_{0} \quad \varphi_{y}(L)=\varphi_{y, L}
$$

where $w(x)[\mathrm{m}]$ is the transversal displacement, $M(x)[\mathrm{Nm}]$ is the bending moment, $E_{M}{ }^{H}(x)$ is homogenized Young modulus for bending, $\varphi_{y}(x)[\mathrm{rad}]$ is the angle of the cross section rotation, $I_{y}\left[\mathrm{~m}^{4}\right]$ is the quadratic moment of the cross section, see Figure 3 ( $N$ and $T_{z}$ are the normal and transversal forces, respectively).
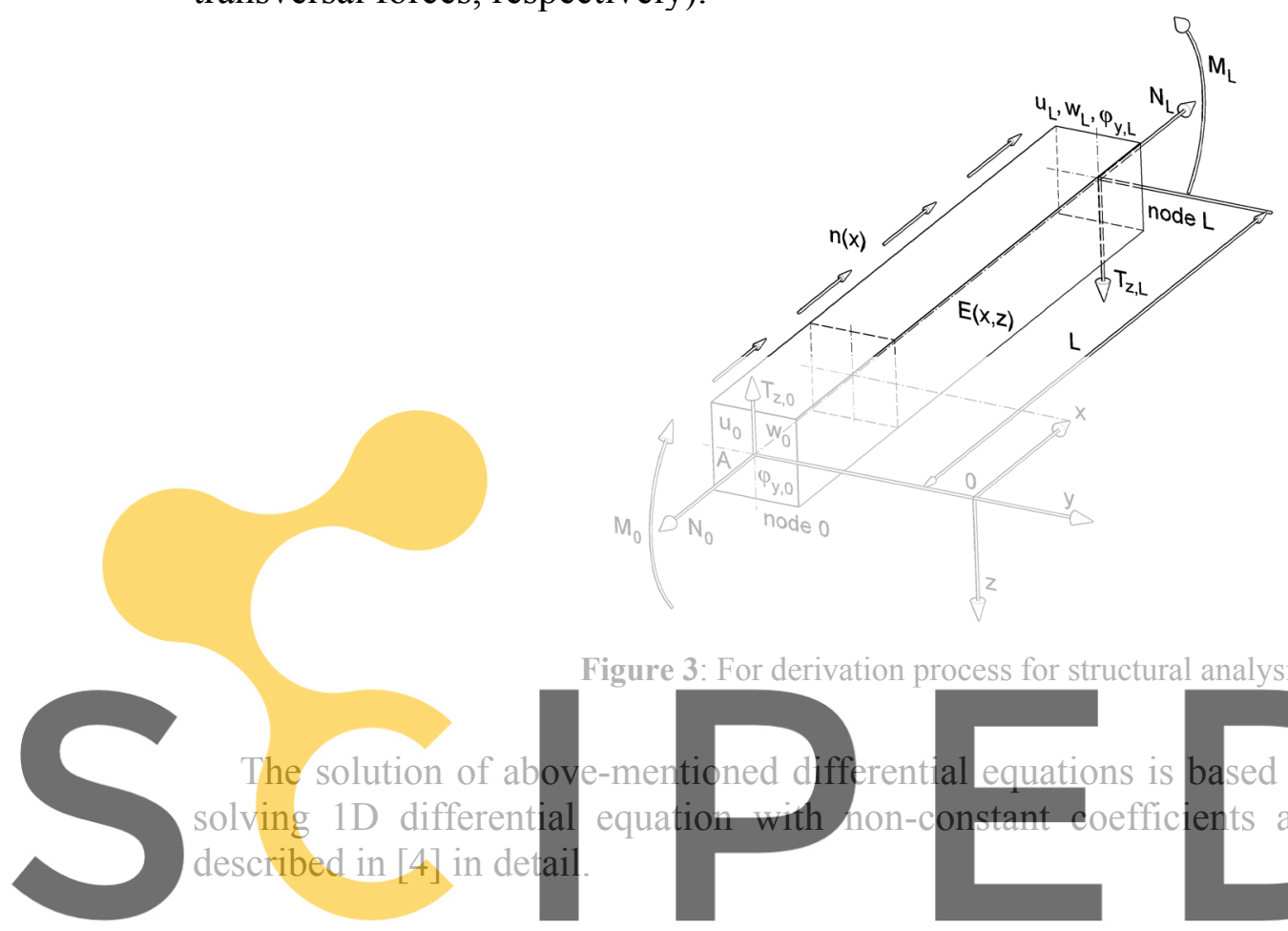

Figure 3: For derivation process for structural analysis

2.2 New beam/link FGM finite element equations

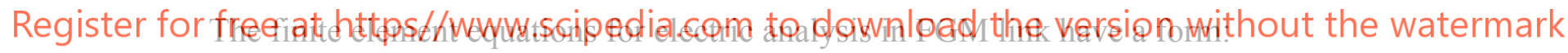

$$
\left[\begin{array}{cc}
c_{0}(L) & -1 \\
\left.c_{0}(L)-\frac{c_{1}(L) c_{0}^{\prime}(L)}{c_{1}^{\prime}(L)}\right) & 1
\end{array}\right] \cdot\left[\begin{array}{l}
\varphi_{0} \\
\varphi_{L}
\end{array}\right]=\left[\begin{array}{c}
\frac{c_{1}(L)}{\sigma_{0}} J_{0} \\
\frac{c_{1}(L)}{c_{1}^{\prime}(L) \sigma_{L}} J_{L}
\end{array}\right]
$$

FEM equations for thermal analysis considering the convective effect, generated heat and Joule heat have a form:

$$
\left[\begin{array}{cc}
c_{0}(L) & -1 \\
-\left(c_{0}(L)-\frac{c_{1}(L) c_{0}^{\prime}(L)}{c_{1}^{\prime}(L)}\right) & 1
\end{array}\right] \cdot\left[\begin{array}{c}
T_{0} \\
T_{L}
\end{array}\right]=\left[\begin{array}{c}
\frac{c_{1}(L)}{\lambda_{0}} q_{0}-\sum_{j=0}^{g} \epsilon_{j} b_{j+2}(L) \\
\frac{c_{1}(L)}{c_{1}^{\prime}(L) \lambda_{L}} q_{L}-\frac{c_{1}(L)}{c_{1}^{\prime}(L)} \sum_{j=0}^{g} \epsilon_{j} b_{j+2}^{\prime}(L)+\sum_{j=0}^{g} \epsilon_{j} b_{j+2}(L)
\end{array}\right]
$$

Derived FEM equations for the structural analysis for pure tensile and compressive stress with coupling to the electro-thermal analysis have a form: 


$$
\left[\begin{array}{cc}
c_{0}(L) & -1 \\
-\left(c_{0}(L)-\frac{c_{1}(L) c_{0}^{\prime}(L)}{c_{1}^{\prime}(L)}\right) & 1
\end{array}\right] \cdot\left[\begin{array}{l}
u_{0} \\
u_{L}
\end{array}\right]=\left[\begin{array}{c}
\frac{c_{1}(L)}{E_{N}^{H} A} N_{0}-c_{1}(L) \alpha_{t, 0} \Delta T_{0}-\sum_{j=0}^{g} \epsilon_{j} b_{j+2}(L) \\
\frac{c_{1}(L)}{c_{1}^{\prime}(L)}\left(\frac{N_{L}}{E_{N}^{H} A}+\alpha_{t, L} \Delta T_{L}-\sum_{j=0}^{g} \epsilon_{j} b_{j+2}^{\prime}(L)\right)+\sum_{j=0}^{g} \epsilon_{j} b_{j+2}(L)
\end{array}\right]
$$

and FEM equations for bending of the beam have general form:

$$
\left[\begin{array}{llll}
K_{11} & K_{12} & K_{13} & K_{14} \\
K_{21} & K_{22} & K_{23} & K_{24} \\
K_{31} & K_{32} & K_{33} & K_{34} \\
K_{41} & K_{42} & K_{43} & K_{44}
\end{array}\right] \cdot\left[\begin{array}{c}
w_{0} \\
\varphi_{y, 0} \\
w_{L} \\
\varphi_{y, L}
\end{array}\right]=\left[\begin{array}{c}
T_{z, 0} \\
M_{0} \\
T_{z, L} \\
M_{L}
\end{array}\right]
$$

The terms $c_{i}(x), c_{i}{ }^{\prime}(x), b_{i}(x), b_{i}{ }^{\prime}(x)$, are the transfer functions and their derivatives (for uniform solution and for particular solution) of the differential equations (1) - (7) which can be calculated by simple numerical algorithm [4]. The term $\epsilon_{j}$ is the $j^{\text {th }}$ coefficient of the polynomial of grade $g$. The members $K_{i j}$ are substituents for combination of the transfer functions for particular $x$ position within the beam element (i.e. transfer constants). For example:

$$
K_{12}=\frac{c_{1}(L) b_{2}^{\prime}(L)-b_{2}(L) c_{1}^{\prime}(L)}{b_{2}(L) b_{3}^{\prime}(L)-b_{3}(L) b_{2}^{\prime}(L)}
$$

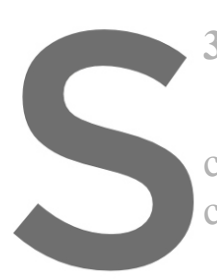

\section{NUMERICAL EXPERIMENT \\ Let us consider actua \\ consists of 3 parts (beams) that lengths are: $L_{1}$ \\ constant rectangular cro

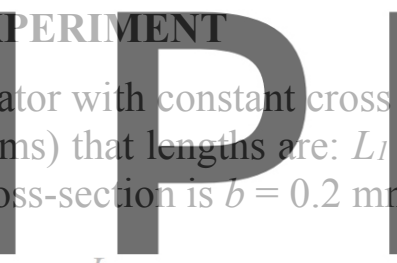

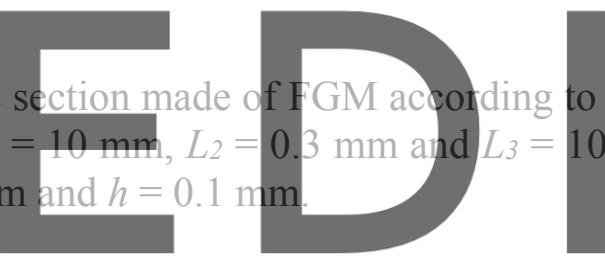

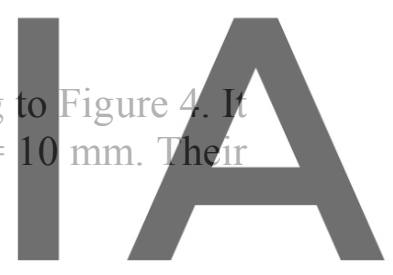

Register for free at.httpst/_ww.s.scipedia.com to download the version without the watermark
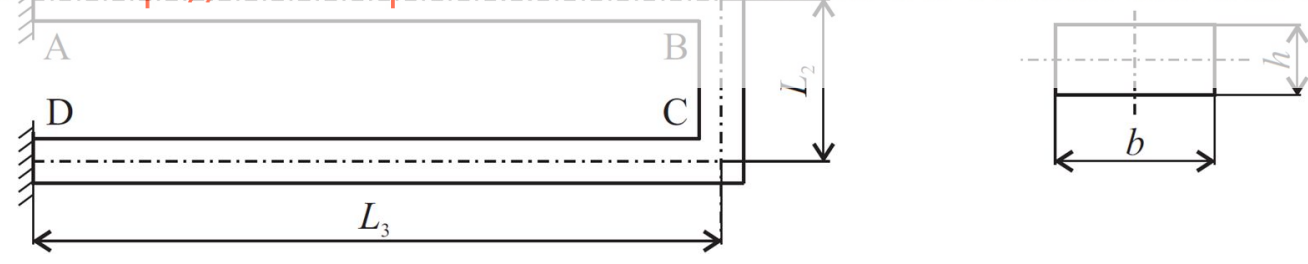

Figure 4: FGM actuator

Actuator is made of FGM that consist of two components: matrix denoted with index $m$ and fibre denoted with index $f$. Material properties of the components are constant (not temperature dependent), Matrix: Young modulus $E_{m}=211 \mathrm{GPa}$, thermal conductivity $\lambda_{m}=80.4 \mathrm{Wm}^{-1} \mathrm{~K}^{-1}$, electric conductivity $\sigma_{\mathrm{m}}=1 \times 10^{7} \mathrm{Sm}^{-1}$, thermal expansion coefficient $\alpha_{t m}=2.18 \times 10^{-5} \mathrm{~K}^{-1}$; Fibre: Young modulus $E_{f}=119 \mathrm{GPa}$, thermal conductivity $\lambda_{f}=401 \mathrm{Wm}^{-1} \mathrm{~K}^{-1}$, electric conductivity $\sigma_{f}=5.96 \times 10^{7} \mathrm{Sm}^{-1}$, thermal expansion coefficient $\alpha_{t f}=1.65 \times 10^{-5} \mathrm{~K}^{-1}$. The variation of material properties is caused by varying volume fraction. Variation of the fibre's volume fraction has been chosen as the polynomial function of longitudinal $(L)$ and lateral $(h)$ directions of individual beams. Coordinates for these directions 
are denoted $x$ and $y$ for the variation of material properties. Through the depth $b$ of the beams the material properties are constant and they are derived from the variation in longitudinal and lateral directions.

Variation of the fibres volume fraction $v_{f}(x, y)$ for the first (from point A to B, see Figure 4) and third beam (from point $C$ to $D$ ) are shown in Figure 5. The constant fibres volume fraction with value $v_{f}(x, y)=0.875$ for the second beam (from point $\mathrm{B}$ to $\mathrm{C}$ ) is considered.
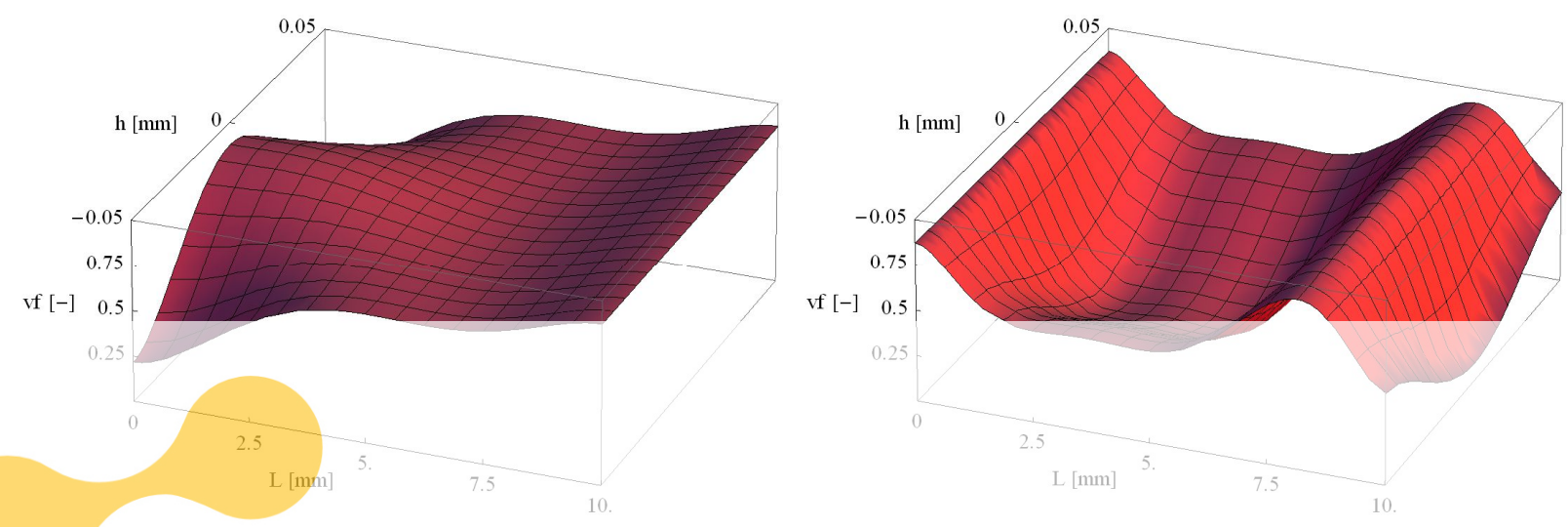

Figure 5: Variation of the fibres volume fraction, left $-1^{\text {st }}$ beam, right $-3^{\text {rd }}$ beam
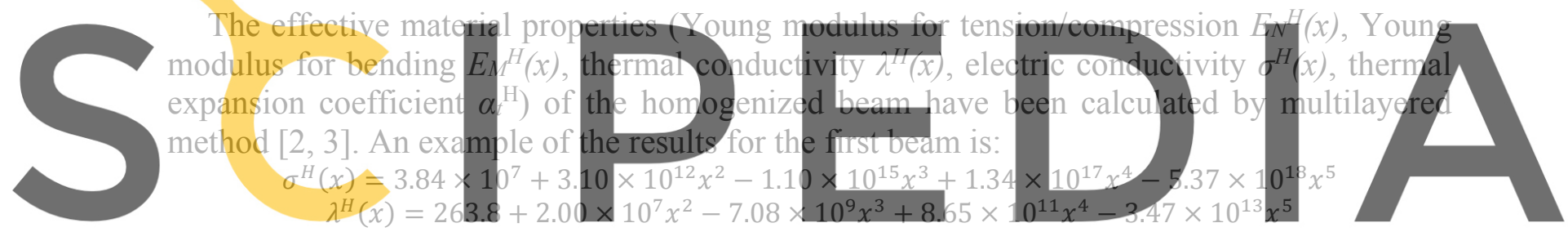

$E_{N}^{H}(x)=1.58 \times 10^{11}-5.74 \times 10^{15} x^{2}+2.03 \times 10^{18} x^{3}-2.48 \times 10^{20} x^{4}+9.96 \times 10^{21} x^{5}$

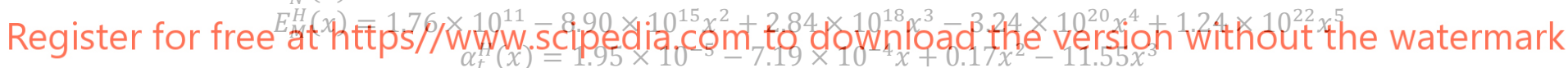

The homogenized thermal conductivity $\lambda^{H}(x)$ for the first and third beam is shown in Figure 6.

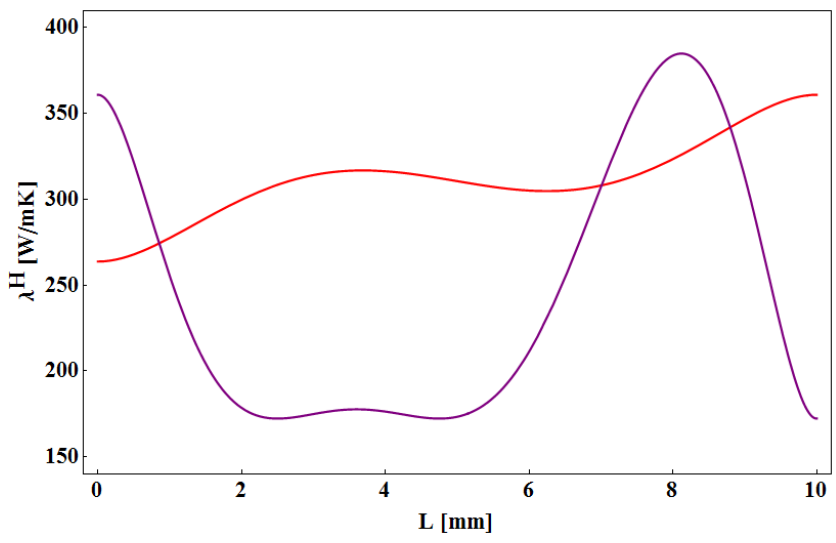

Figure 6: Homogenized thermal conductivity, red $-1^{\text {st }}$ beam, purple $-3^{\text {rd }}$ beam 
The applied constrains and loads are:

- electric potential and current: $\varphi_{A}=0 \mathrm{~V}, I_{D}=2 \mathrm{~A}$;

- temperatures: $T_{A}=25{ }^{\circ} \mathrm{C}, T_{D}=25{ }^{\circ} \mathrm{C}$;

- fixed support: $u_{A}=0 \mathrm{~m}, u_{D}=0 \mathrm{~m}$,

$$
\begin{aligned}
& w_{A}=0 \mathrm{~m}, w_{D}=0 \mathrm{~m}, \\
& \varphi_{y, A}=0 \mathrm{rad}, \varphi_{y, D}=0 \mathrm{rad}
\end{aligned}
$$

The coupled electro-thermo-mechanical analysis of FGM actuator has been done using our new FGM beam/link finite elements. The calculation has been done using software MATHEMATICA. Only three our new finite elements have been used (one for each part). The same problem has been solved using a fine mesh - 51600 of PLANE223 elements of the FEM program ANSYS (see Figure 7). The average relative difference $\Delta[\%]$ between quantities calculated by our method and the ANSYS solution has been evaluated.
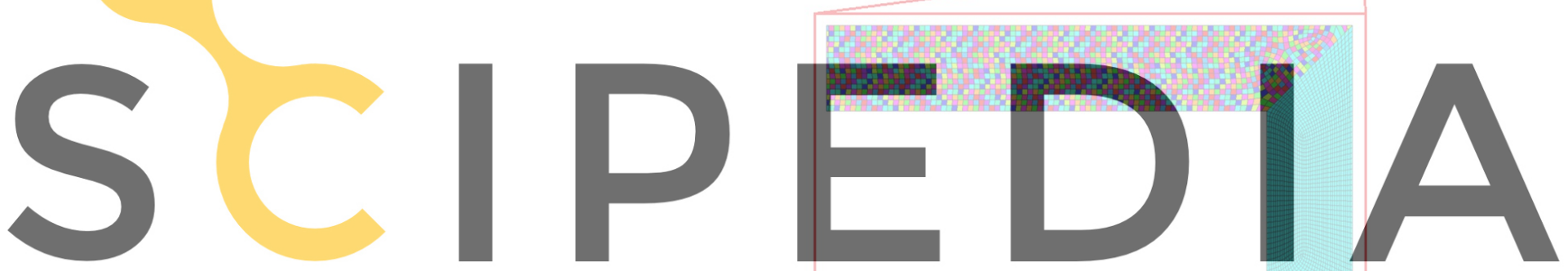

Register for free at https//www.scipedia.com to co

Figure 7: Elements of the FGM actuator in ANSYS, the first and third beam are made of FGM, the second beam has constant material properties

Electric analysis was performed as the first solution and the nodal electric variables have been obtained (see Table 1).

Table 1: The results of electric analysis

\begin{tabular}{cccc}
\hline electric potential [V] & new element & ANSYS & $\Delta[\%]$ \\
\hline$\varphi_{B}$ & 0.0220 & 0.0219 & 0.46 \\
\hline$\varphi_{C}$ & 0.0226 & 0.0245 & -7.76 \\
\hline$\varphi_{D}$ & 0.0538 & 0.0557 & -3.41 \\
\hline
\end{tabular}

Thermal analysis was performed as the second one. Distributed thermal load - Joule heat caused by electric current was included into the analysis. The results of thermal analysis are presented in Table 2 . 
Table 2: The results of thermal analysis

\begin{tabular}{cccc}
\hline temperature $\left[{ }^{\circ} \mathrm{C}\right]$ & new element & ANSYS & $\Delta[\%]$ \\
\hline$T_{B}$ & 76.54 & 78.88 & -2.97 \\
\hline$T_{C}$ & 76.93 & 80.30 & -4.20 \\
\hline
\end{tabular}

Structural analysis was performed as the last analysis, where thermal forces caused by thermal expansion were included into the model. The results of structural analysis are the displacements $u$ for longitudinal direction and $w$ for transversal direction (see Table 3 ).

Table 3: The results of structural analysis

\begin{tabular}{cccc}
\hline displacement $[\mathrm{mm}]$ & new element & ANSYS & $\Delta[\%]$ \\
\hline $\boldsymbol{u}_{B}$ & 0.0061 & 0.0057 & $\mathbf{7 . 0 2}$ \\
\hline$w_{B}$ & 0.0166 & 0.0141 & 17.7 \\
\hline$u_{C}$ & 0.0071 & 0.0065 & 9.23 \\
\hline$w_{C}$ & 0.0163 & 0.0139 & 17.3 \\
\hline
\end{tabular}

As it can be seen from Tables 1 - 3, there are considerable differences between results obtained by our new element and FEM program ANSYS especially for the analyses (e.g. structural) that are based on the results from preliminary analyses (e.g. thermal and electric

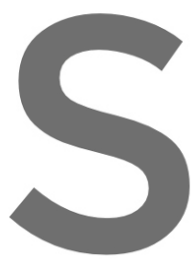
analyses). This is causer

(considered in the beam

current and heat flow in th

theory.

The comparison
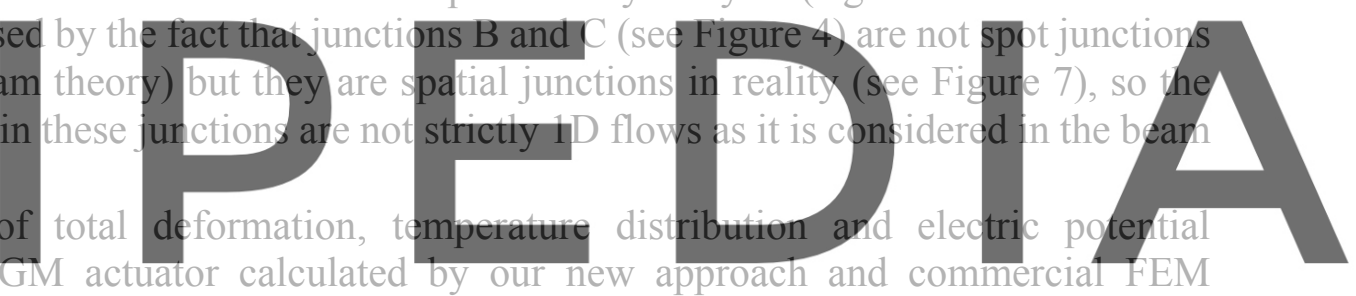

distribution of the FGM actuator calculated by our new approach and commercial FEM program ANSYS is shown in Figure 8.

Register for free at https//www.scipedia.com to download the version without the watermark 

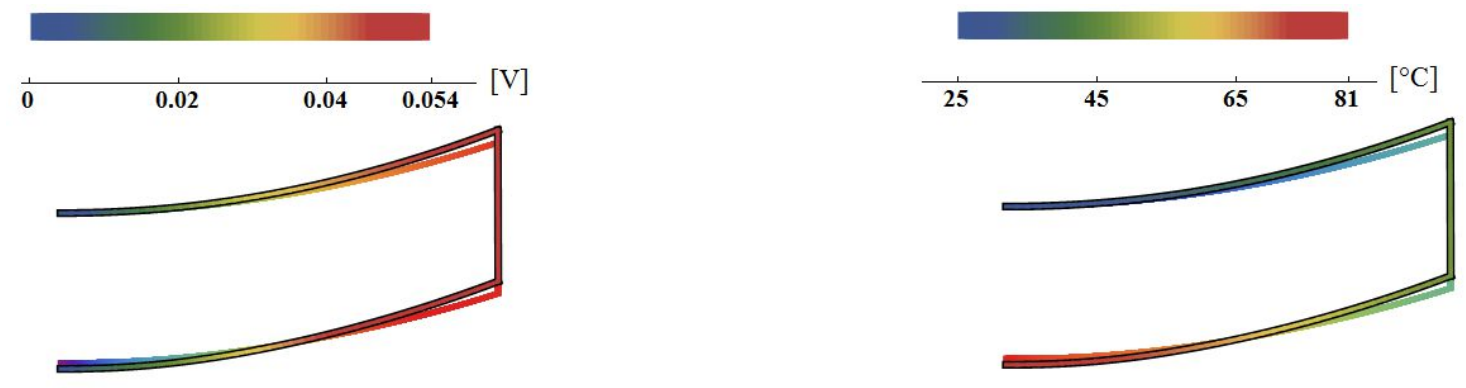

- ANSYS $\square$ new element

- ANSYS $\square$ new element

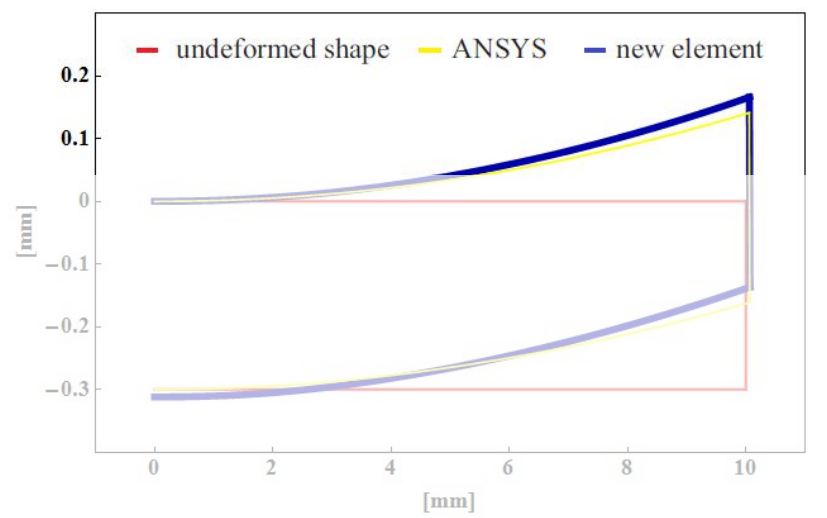

Figure 8: Results of electro-thermo-mechanica analy
bottom - displacentent (
4 CONCLUSIONS
New FEM equations for weak coupled static
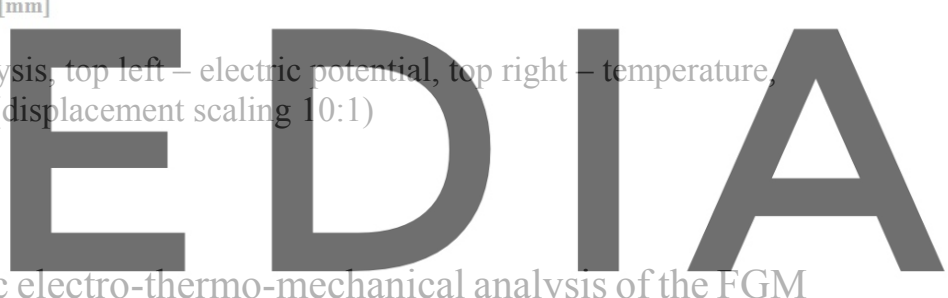

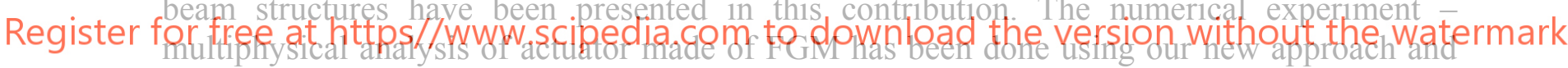
obtained results have been compared with ones obtained by solution with commercial software

ANSYS.

\section{ACKNOWLEDGEMENT}

This work was supported by the Slovak Grant Agency: VEGA 1/0081/18, KEGA 011STU4/2020 and APVV-19-0406.

\section{REFERENCES}

[1] Murin, J., Kutis, V. Improved mixture rules for composite (FGMs) sandwich beam finite element. In: Computational Plasticity IX. Fundamentals and Applications. Barcelona, Spain, (2007): 647-650.

[2] Kutis, V., J. Murın, J., Belak, R. and Paulech, J. Beam element with spatial variation of material properties for multiphysics analysis of functionally graded materials. Computers and Structures, Vol. 89, (2011).

[3] Murin, J., Kutis, V., Paulech, J. and Hrabovsky, J. Electric-Thermal Link Finite Element Made of a FGM with Spatial Variation of Material Properties. Composites Part B: 
Engineering, Vol. 42, (2011).

[4] Rubin, H. Solution of differential equations of arbitrary order with polynomial coefficients and application to a statics problem. ZAMM 76 (1996), 105-117.
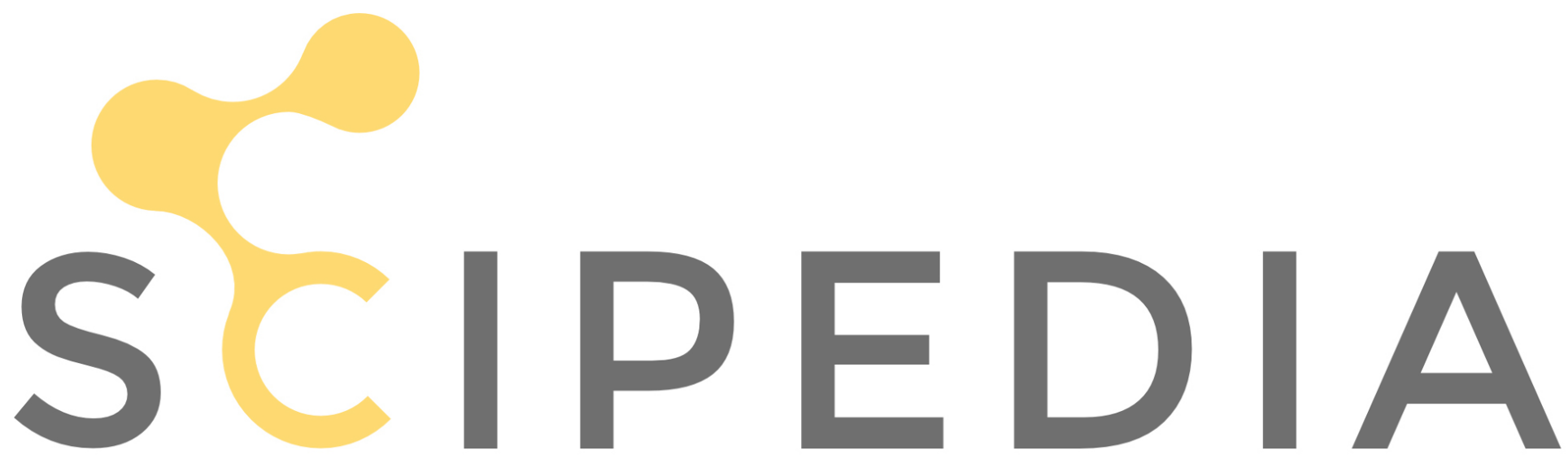

Register for free at https//www.scipedia.com to download the version without the watermark 